\title{
Prophylactic Clip Closure for Mucosal Defects is Associated with Reduced Adverse Events After Colorectal Endoscopic Submucosal Dissection: A Propensity-Score Matching Analysis
}

\section{Jun Omori ( $\square$ 67trocadero@nms.ac.jp )}

Department of gastroenterology, Nippon Medical School, Graduate School of Medicine https://orcid.org/0000-0002-4375-5070

\section{Osamu Goto}

Department of gastroenterology, Nippon Medical School, Graduate School of Medicine Tsugumi Habu

Department of Gastroenterology, Nippon Medical School, Graduate School of Medicine Yumiko Ishikawa

Department of Gastroenterology, Nippon Medical School, Graduate School of Medicine Kumiko Kirita

Department of Gastroenterology, Nippon Medical School, Graduate School of Medicine

\section{Eriko Koizumi}

Department of Gastroenterology, Nippon Medical School, Graduate School of Medicine

\section{Hiroto Noda}

Department of Gastroenterology, Nippon Medical School, Graduate School of Medicine

\section{Kazutoshi Higuchi}

Department of Gastroenterology, Nippon Medical School, Graduate School of Medicine

\section{Takeshi Onda}

Department of Gastroenterology, Nippon Medical School, Graduate School of Medicine

\section{Teppei Akimoto}

Department of Gastroenterology, Nippon Medical School, Graduate School of Medicine Naohiko Akimoto

Department of Gastroenterology, Nippon Medical School, Graduate School of Medicine Norio Itokawa

Department of Gastroenterology, Nippon Medical School, Graduate School of Medicine Mitsuru Kaise

Department of Gastroenterology, Nippon Medical School, Graduate School of Medicine Katsuhiko Iwakiri

Department of Gastroenterology, Nippon Medical School, Graduate School of Medicine 


\section{Research Article}

Keywords: colorectal endoscopic submucosal dissection, mucosal closure, adverse events

Posted Date: February 24th, 2022

DOI: https://doi.org/10.21203/rs.3.rs-1049912/v1

License: (c) (i) This work is licensed under a Creative Commons Attribution 4.0 International License. Read Full License

Version of Record: A version of this preprint was published at BMC Gastroenterology on March 26th, 2022. See the published version at https://doi.org/10.1186/s12876-022-02202-3. 


\section{Abstract}

Background: Whether prophylactic endoscopic closure after colorectal endoscopic submucosal dissection (ESD) reduces the risk of postoperative adverse events remains unclear due to variabilities in lesion characteristics. Therefore, we conducted a retrospective study using propensity-score matching to evaluate the efficacy of prophylactic clip closure in preventing postoperative adverse events after colorectal ESD.

Methods: This single-center retrospective cohort study included 219 colorectal neoplasms which were removed by ESD. The patients were allocated into the closure and non-closure groups, which were compared before and after propensity-score matching. Post-ESD adverse events including major and minor bleeding and delayed perforation were compared between the two groups.

Results: In the present study, 97 and 122 lesions were allocated to the closure and non-closure groups, respectively, and the propensity-score matching created 61 matched pairs. The rate of adverse events was significantly lower in the closure group than in the non-closure group ( $8 \% \mathrm{vs.} 28 \%, \mathrm{P}=0.008)$. Delayed perforation occurred in two patients in the non-closure group, whereas no patient in the closure group developed delayed perforation. In contrast, there were no significant differences in other postoperative events including the rate of abdominal pain, fever; white blood cell count, and C-reactive protein; and appetite loss between the two groups.

Conclusions: The propensity-score matching analysis demonstrated that prophylactic closure was associated with significantly reduced rate of total adverse events after colorectal ESD. When technically feasible, mucosal defect closure after colorectal ESD may be helpful for a favorable postoperative course.

\section{Background}

Endoscopic submucosal dissection (ESD), which has been gaining wider acceptance for the treatment of superficial colorectal neoplasms due to lessinvasiveness and high curability potential, is however a demanding procedure, partially due to technical difficulties and higher incidence of adverse events [1]. Specifically, the rates of delayed bleeding and delayed perforation, common major adverse events after colorectal ESD, are $0.7 \%-3.1 \%[2-5]$ and $0.3 \%-0.7 \%$, respectively[2,3].Delayed perforation is proposed to be related to excessive coagulation in the muscularis propria. Subtle bleeding is a minor adverse event observed after ESD in some patients. Although not a clinically relevant presentation invariably requiring endoscopic intervention, hematochezia may causeprolonged hospitalization or re-admission. Therefore, prevention of postoperative bleedingshould be aimed regardless of the volume of blood loss.

Mucosal defect closure using endoscopic clipsafter endoscopic resectionis expected to reduce the rate of delayed bleeding. Several large retrospective studies showed that prophylactic clipping closure for $>2 \mathrm{~cm}$ lesions was beneficial for preventing delayed bleeding afterpolypectomy or endoscopic mucosal resection $(E M R)[6,7]$, whereas several randomized controlled trials demonstrated that clip placement after 
polypectomy or EMRdid not prevent delayed bleeding[8-11]. Additionally, a meta-analysis found that the impact of prophylactic clipping after colorectal endoscopic resection for polyps $<2 \mathrm{~cm}$ was unexpectedly small [12], whichmight have been due to the lower rate of postoperative bleeding observedin small polyps.Alternatively, few reports investigatedthe utility of clip closure after colorectal ESD [13-16], since the closure of large mucosal defects by clipping after colorectal ESD is considered technically challenging.Several closure techniques for large mucosal defects after ESD have been recently introduced with the aim to reduce postoperative adverse events after ESD [17-22], and closeable target lesions have been expanded in size and location; however, some lesions remain difficult or impossible to completely close.

We introduced the prophylactic clip closure for post-ESD mucosal defects in practice since April 2018, expecting the preventative effect for delayed adverse events. After a transitional period, we are trying to

perform it for all lesions if considered technically possible. We therefore conducted a retrospective study with propensity-score matching to evaluate the efficacy of prophylactic clip closure for the prevention of postoperative adverse events after colorectal ESD.

\section{Methods}

\section{Study design and patients}

In all, 242 patients with 259 superficial colorectal neoplasms underwent ESDbetween January2018 and August 2020 at the study hospital. All ESD procedures were performed by five experienced endoscopists in this unit. For this study, we excluded cases of multiple lesions that were simultaneously treated by ESD (33 lesions in 16 patients) to clearly identify lesions responsible for the study outcomes;furthermore, seven non-adenomatous lesions (threeneuroendocrine tumors, two mucosaassociated lymphoid tissue lymphomas, one ganglioneuroma, andone ulcerative colitis-related dysplasia) were excluded due to possible differences in vascularity. Consequently, 219 colorectal neoplasms in 219 patients were enrolled in this retrospective cohort study.

All lesions were diagnosed as node-negative cancer by white-light endoscopy followed by magnifying endoscopywith narrow-band imaging and chromoendoscopyand were classified as appropriate lesions for treatmentwith ESD based theJapan Gastroenterological Endoscopy Society guidelines for colorectal ESD[23]. All patients undergoing ESD were fully informed regarding the need for treatment, ESD risks and benefits, and alternative treatments includingEMR and surgical resectionand provided written informed consent to undergo ESD. Regarding the continuation of antithrombotic agents, we followed the "Guidelines for gastroenterological endoscopy in patients undergoing antithrombotic treatment." of the Japan Gastroenterological Endoscopy Society; additionally, we judged to take antithrombotic agents continuously or withdrawn[24,25].This study was approved by the medical ethical committees of Nippon Medical School. (Approval No. 30-02-1077) 
All procedures were performed using a standard colonoscope (PCF-H290ZI or PCF-Q260Al; Olympus Co. Ltd, Tokyo, Japan)under insufflation with carbon dioxide. The disposable distal attachment was mounted onto the tip of the endoscope. An electrosurgical current generator(VIO300D; Erbe Elektromedizine, Tubingen, Germany) was used for electrical dissection and coagulation. TheDualKnife (KD-655Q; Olympus) orthe FlushKnife (DK2620J; Fujifilm Co. Ltd., Tokyo, Japan)knife was used for primary electrocauterization, andhyaluronic acid solution was used as the injection liquid.The tip of the electrocautery knife or hemostatic forceps was used for intraoperative bleeding and prophylactic hemostasis for visible nonbleeding vessels as well as for cauterization of the mucosal defect immediately after the resection. Patients with favorable physical examination, blood test, and X-ray results were allowed to drink water on postoperative day (POD) 1 and to have soft food on POD1 or 2 following ESD. Patients with noticeable bloody stools were defined as experiencingdelayed bleedingand underwent endoscopic hemostasis. On POD 3 or later, allthe patients were discharged and told to monitor whether bleeding occurred during the interval between discharge and one-month outpatient follow-up visit. Emergence of abdominal pain and free air in the abdominal space in the absence of intraoperative perforationby imaging modalities was used to define delayed perforation.

\section{Prophylactic clipping}

Since April 2018 (the initial one year as a transitional period), prophylactic clipping wasperformed for all lesions in which complete closure was considered to be technically achievable by the endoscopist regardless of muscular damages or defect size.Mucosal defects remained open in cases where the endoscopist determined that clip closure was difficult or should not be performed due to large size, long ESD duration, and inability to remove the lesion en bloc.

For the closure of post-ESD mucosal defects, EZ clips (HX-610-090L; Olympus)and repositionable clips (Zeo clips; Zeon Medical Inc., Tokyo, Japan or Quick Clip Pro; Olympus) were used. First, the intraluminal air was suctioned to bring the two mucosal edgesclosertogether. Next, one arm of the clip was attached to the proximal mucosal edge, followed by hooking of the other clip arm to the distal mucosal edge using the endoscope.Then, the clip was gently closed and confirmed to correctly grasp both edges. The closure was completed by repeating the procedure to bridge the remnant gaps between the two edges (Fig.1a). In cases where the edges were too far from each another for successful closure using clips, half of the defect was initially closed by clips to bridge the mucosal edge and submucosal surface at the center of the defect, followed by the closure of the remaining half of the mucosal edges by clipping (Fig.1b,1c).If the clipping procedure failed, the closure of mucosal defect was abandoned,and terminated the procedure keeping the mucosal defect not completely closed.

\section{Outcome measures and propensity-score matching}

The study patients were allocated to the closure and non-closure groups. The closure group included patients in whom the mucosal defect was completely closed by one or more clips that were placed at $>5$ $\mathrm{mm}$ intervals. The non-closure group included patients in whom clip closure wasnot attempted or was incomplete due to technical difficulties. 
To investigate the efficacy and safety of prophylactic clip closure for mucosal defects, postoperative bleeding and perforation after colorectal ESD were evaluated as the primary endpoint. Postoperative bleeding was categorized as major and minor bleeding.Major bleeding was defined as the presence of clinical evidence for bleeding manifesting as hematochezia requiringendoscopic hemostasis, and minor bleeding was defined as the presence of a small amount of hematochezia monitored without endoscopic intervention.Data on abdominal pain, fever defined as $>37.5^{\circ} \mathrm{C}$, C-reactive protein level, andwhite blood cell (WBC) count on POD 1 as well as data on appetite loss, defined as $<50 \%$ meal intake on POD 2,were evaluated as secondary endpoints.

As shown in Fig.2, the two groups were compared after propensity-score matching to control for factors that might influence ESD treatment outcomes and adverse events. To assessthese potential factors, univariate analyses were performed with the explanatory variables of age, sex, antithrombotic agents administered, lesion location, specimen size, tumor size, and procedure time of ESD. To minimize inherent bias, the two groups were matched in a 1:1 ratio, with 61 patients in each group, and propensity-score matching was used to adjust for the six covariates determined by the univariate analyses, includingantithrombotic agents administered, lesion location, morphology, specimen size, tumor size, and procedure time of ESD.The caliper width of the matching was 0.0456 .

\section{Statistical analysis}

Pearson's chi-square test or Fisher's exact test was used to analyze categorical data for comparison of proportions. Student's $t$ test was used for unpaired data to determine differences in means between two groups.Differences were considered statistically significant with a $P$ value of $<0.05$. Data were evaluated using the SPSS statistical software package version25 (IBM, New York, NY, USA).

\section{Results}

Analysis before propensity-score matching

Among the 219 lesions, 97and 122were allocated to the closure and non-closure groups, respectively (Fig.2).Table 1 shows the patient characteristicsbefore propensityscore matching. The mean patient age was $69.8 \pm 10.7$ years in the closure group and $69.7 \pm 11.3$ years in the non-closure group.There weresignificant differences in the proportion of patients treated with antithrombotic agents $(26 \% \mathrm{vs.} 15 \%$, $P=0.041)$, proportion of 0 -lla lesions ( $78 \%$ vs. $89 \%, P=0.041)$, proportion of rectal lesions ( $8 \%$ vs. $31 \%, P$ $=0.001)$, mean specimen size $(40.1 \pm 12.1$ vs. $47.7 \pm 16.1 \mathrm{~mm}, \mathrm{P}<0.001)$, mean tumor size $(26.8 \pm 11.3$ vs. $34.8 \pm 16.6 \mathrm{~mm}, \mathrm{P}<0.001)$, and procedure time of ESD $(61.0 \pm 29.0$ vs $85.3 \pm 48.7 \mathrm{~min}, \mathrm{P}<0.001)$ between the closure and non-closure groups, respectively.The proportion of patients with concurrent lesions removed by EMR or polypectomy was not significantlydifferent between the two groups. The en bloc resection in the closure and non-closure groups were $100 \%$ and $98 \%$, respectively, with no significant difference between the two groups. In the closure group, the mean procedure time for closure was $12.4 \pm$ 5.2 (range, 4.0-25.0) minutes and the mean number of clips required for closure was $9.8 \pm 3.2$ (range, 321). 
The outcome data are presented in Table2. The total number of adverse events after colorectal ESD, including delayed perforation and post-ESD bleeding, was significantly higher in the non-closure group than inthe closure group( $28 \%$ vs. $6 \%, \mathrm{P}<0.001)$.Similarly, the proportion of patients with fever was significantly higher in the non-closure group than in the closure group $(12 \% \mathrm{vs.} 2 \%, \mathrm{P}=0.019)$. However, there were no significant differences in the proportion of patients with abdominal pain, WBC count,Creactive protein levels, andappetite loss between the two groups.

\section{Propensity-score matchinganalysis}

Propensityscore matching controlled for differences in the proportion of patients taking antithrombotic agents, lesion location, morphology, specimen size, tumor size, and procedure time of ESD, which weresignificantly different between the two groups by univariate analysis. Consequently, propensityscore matching created 61 matched pairs (Fig.2). This model yielded a c-statistic of 0.776 , indicating its ability to differentiate between thetwo groups.

Table3 shows the characteristics of the two groups after propensity-score matching.The groups were similar in age $(68.8 \pm 11.0$ vs. $68.5 \pm 11.9$ years, $P=0.890)$, proportion of males $(62 \%$ vs. $62 \%, P=$ $1.000)$,proportion of patients taking antithrombotic agents( $23 \%$ vs. $21 \%, P=0.827)$,proportion of rectal lesions $(13.1 \%$ vs. $13.1 \%, P=1.000)$, specimensize ( $41.5 \pm 11.9$ vs. $42.9 \pm 10.7 \mathrm{~mm}, P=0.503)$, tumor size (29.1 $\pm 11.6 v s$. $29.2 \mathrm{~mm} \pm 12.1, \mathrm{P}=0.954)$, and procedure time of ESD $(66.5 \pm 28.1 \mathrm{vs}$. $68.3 \pm 30.6 \mathrm{~min}, \mathrm{P}$ $=0.731)$. Table4 lists the outcomes afterpropensityscore matching. Regarding adverse events, two patients in the non-closure group experienced post-ESD delayed perforation whereas no patient in the closure group developed post-ESD delayed perforation. The rate of adverse events, including delayed bleeding and delayed perforation, was significantly lower in the closure group than in the non-closure group ( $8 \%$ vs. $28 \%, P=0.008$ ). Furthermore,the delayed bleeding rate was significantly lower in the closure group than in the non-closure group( $8 \%$ vs. $25 \%, P=0.025)$. In contrast, there were no significant differences in the proportion of patients with abdominal pain, fever, WBC count, C-reactive protein levels, and appetite loss between the two groups.

\section{Discussion}

In the present study, we demonstrated using propensity score matching analysisthatprophylactic clip closure for mucosal defectsafter colorectal ESDwas associated with reduced postoperative adverse events including minor delayed bleeding. Although our findingscannot be generalized regarding technical difficulties, the results suggest that mucosal closure may effectively reduce postoperative adverse events and,therefore, mayprovide a safer and more comfortable ESD, when complete closure is achieved.

Several randomized controlled trials and one meta-analysis on prophylactic clip closure after EMR/polypectomy for small lesions showed that this approach was not beneficial in preventingdelayed bleeding [8-12].Indeed, the Japan Gastroenterological Endoscopy Societyguidelines forESD/EMRstate that prophylactic clipping [23], whichmay have a limited effect after the endoscopic resection of colorectal polyps, may be effective in patients at high risk of postoperative bleeding,such as those with 
large lesions and those receiving antithrombotic therapy;however, the evidence level is low. Particularly in $\mathrm{EMR} /$ polypectomy for small lesions, delayed bleeding may not besufficient to prove the efficacy of prophylactic clip closure [12]. In contrast, the risk of adverse events is considered to be higher after ESD compared with EMR.Nevertheless, to date, no study has extensively evaluated the utility of prophylactic clipping.

The lack of evidence on the utility of prophylactic clipping after colorectal ESD may be related to the fact that clip closureis technically difficult and its success depends largely on lesion characteristics. In practice, clip closure is attempted after empirical confirmation that the clip is technically durable; therefore, we acknowledge the apparent selection biasin clip-closure applications. As expected, there were significant differences in lesion characteristics between the closure and non-closure groups. Therefore,weconducted propensityscore matching to analyze the trueefficacy of prophylactic clip closurewithout the confounding effects of technical issues. The present study results suggest that defect closure after colorectal ESD should be considered in all patients whenever feasible.Furthermore, these results suggest that other closure techniques, such as endoscopic suturing, may also be effective.

The present study found that endoscopic closure using conventional clips reduced the risk of delayed perforation and delayed bleeding including minor bleeding. Major bleeding is primarily considered as apost-ESD adverse event; however, other subclinical adverse events, such as minor bleeding,that are problematic and stressful for patients may require treatment. Moreover, it can be challenging formedical staff to decide whether close monitoringby hospitalizationand/or emergency endoscopy should be performed in patients with minor bleeding. However, delayed perforationsare extremely severe. Nevertheless,evaluation in large cohorts is difficult, since delayed perforations are rare,and effective countermeasures remain unknown.

In the present study, minor bleeding and delayed perforation were included as postoperative adverse events, and our analyses revealedthat prophylactic clip closure may prevent unexpected eventsincluding these two undoubtedly severeevents. Although prophylactic clip closure required an extra cost of clips and extra time of clipping after ESD, reduction of risk after ESD by clipping is more beneficial than prophylacticclip closure sinceit is a less invasive treatment option. Furthermore, clip closure is a conventional technique for experienced endoscopists and clip hemostasis is superior, since muscle layer damage is prevented.

Post-polypectomy syndromeis characterized by local peritoneal inflammation in the absence of apparent perforation that candevelop after colorectal ESD. This presentation is related to excessive coagulation in the muscularis propria and to large mucosal defects after colorectal ESD. Some patients have localized abdominal pain, fever, leukocytosis, and appetite loss. In the present study, there were no significant differencesin the proportion of patients with abdominal pain, those with fever, WBC count, and C-reactive protein level, andappetite loss between the closure and non-closure groups, whichsuggested that postpolypectomysyndrome occurred equally between the two groups and that clip closure did not affect the rate of this syndrome in the present study. 
Various closure devices and methods, such as slip knot clip suturing [17-19], endoscopic mucosasubmucosa clip closure [20,21], overstitch system [26], and endoscopic hand suturing [27,28], have been reported for the closure of artificial wounds after endoscopic resection.In the present study, we occasionally performedthe endoscopic mucosa-submucosa clip closure method in ESDfor mucosal defectsthat were too large to be closed in a single action(Fig. 1b,1c).Additionally, we chose repositionable clips and performedthe "hold-and-drag" closure technique inallcases[22] (Fig.1d,1e,1f).Every technique has advantages and disadvantages; therefore,the selection of the closure technique depending on the situation and the endoscopist's preferenceshould be acceptable to achieve complete closure. Although lesions that were easily closed by clip may often be easily resectedby ESD due to their small size, specifictypes of small lesions with severe fibrosis, abundant blood vessels, or bleedingmay be difficult to resect by ESD. Therefore, clip closure may be effective for postoperative adverse events, sincespecifictypes of small lesions with severe fibrosis, abundant blood vessels, or bleeding have a high rate of muscle layer damage during ESD, even if the mucosal defects after ESD are small.

The present study has several limitations. First, the sample size was small; therefore, studies with larger cohorts are neededto confirm the efficacy of endoscopic closure. Second, we were unable todirectly compare the efficacy of prophylactic clipping between the closure and non-closure groups, andprospective randomized studies are needed to establish evidence. Third, clip closure for large mucosal defects after colorectal ESD requires certain endoscopic skills and experience. Fourth,clip closure may fail for lesions in certain locations and situations.Large lesions are typically more difficult to close than small lesions. Therefore, it is increasingly difficult to evaluate the efficacy of prophylactic clipsfor large lesions. Furthermore, in our study, large lesions were likely to be removed by propensity score matchingdue to the characteristics of the dataset.

\section{Conclusion}

Propensityscore matching analysis demonstrated that prophylacticclip closure was associated with significantly reduced total adverse events after colorectal ESD. This result should be confirmed with prospective randomized trials.

\section{Abbreviations}

ESD: endoscopic submucosal dissection; MALT: mucosa-associated lymphoid tissue; EMR: endoscopic mucosal resection; POD: postoperative day;WBC: white blood cell; SD: standard deviation

\section{Declarations}

\section{Ethics approval and consent to participate}

This study conducted in accordance with the ethical standards of thedeclaration of Helsinki. The requirement for informed consent from thepatients was waived because of the retrospective nature of 
this study, andthis study was approved by the medical ethical committees of Nippon Medical School. (Approval No. 30-02-1077)

\section{Consent for publication}

Not applicable.

\section{Availability of data and materials}

The datasets used and analyzed in the current study are available from the corresponding author on reasonable request.

\section{Competing interests}

The authors declare that they have no competing interests.

\section{Funding}

This study received no financial support.

\section{Authors' contributions}

JO and OG designed and conceived this study. TH, YI, KK, EK, HN, TO, TA, NA, MK, and IK collected the data. JO analyzed and interpreted the results and drafted of the manuscript. OG performed critical revision of the article for important intellectual content. NI supported statistical analyses. All authors read and approved the final manuscript.

\section{Acknowledgements}

We would like to thank Takamitsu Umeda, M.D. at Nippon Medical School Hospital for collecting data in this study.

\section{References}

1. Hurlstone DP, Sanders DS, Cross SS, et al. Colonoscopic resection of lateral spreading tumours: a prospective analysis of endoscopic mucosal resection. Gut 2004;53(9):1334-1339.

2. Fujishiro M, Yahagi N, Kakushima N, et al. Outcomes of endoscopic submucosal dissection for colorectal epithelial neoplasms in 200 consecutive cases. Clin Gastroenterol Hepatol 2007;5(6):678683.

3. Isomoto $\mathrm{H}$, Nishiyama $\mathrm{H}$, Yamaguchi $\mathrm{N}$, et al. Clinicopathological factors associated with clinical outcomes of endoscopic submucosal dissection for colorectal epithelial neoplasms. Endoscopy 2009;41(8):679-683.

4. Watabe $\mathrm{H}$, Yamaji Y, Okamoto $\mathrm{M}$, et al. Risk assessment for delayed hemorrhagic complication of colonic polypectomy: polyp-related factors and patient-related factors. Gastrointest Endosc 
2006;64(1);73-78.

5. Okamoto K, Watanabe T, Komeda Y, et al. Risk factors for postoperative bleeding in endoscopic submucosal dissection of colorectal tumors. Oncology. 2017;93suppl 1:35-42.

6. Liaquat H, Rohn E, Rex DK. Prophylactic clip closure reduced the risk of delayed postpolypectomy hemorrhage: experience in 277 clipped large sessile or flat colorectal lesions and 247 control lesions. Gastrointest Endosc 2013;77(3):401-407.

7. Dior M, Coriat R, Tarabichi S,et al. Does endoscopic mucosal resection for large colorectal polyps allow ambulatory management? Surg Endosc 2013;27(8):2775-2781.

8. Shioji K, Suzuki Y, Kobayashi M, et al. Prophylactic clip application does not decrease delayed bleeding after colonoscopic polypectomy. Gastrointest Endosc 2003;57(6):691-694.

9. Dokoshi T, Fujiya M, Tanaka K, et al. A randomized study on the effectiveness of prophylactic clipping during endoscopic resection of colon polyps for the prevention of delayed bleeding. Biomed Res Int 2015;2015:1-6.

10. Mori $\mathrm{H}$, Kobara $\mathrm{H}$, Nishiyama $\mathrm{N}$, et al. Simple and reliable treatment for post-EMR artificial ulcer floor with snare cauterization for 10- to 20-mm colorectal polyps: a randomized prospective study (with video). Surg Endosc 2015;29(9):2818-2824.

11. Matsumoto $\mathrm{M}$, Kato $\mathrm{M}, \mathrm{Oba} \mathrm{K}$, et al. Multicenter randomized controlstudy to assess the effect of prophylactic clipping on post-polypectomy delayed bleeding. Dig Endosc 2016;28(5):570-576.

12. Nishizawa T, Suzuki $H$, Goto $\mathrm{O}$, et al. Effect of prophylactic clipping in colorectal endoscopic resection: a meta-analysis of randomized controlled studies. U Euro Gastroenterol J 2017;5(6):859867.

13. Kinoshita S, Nishizawa T, Fujimoto A, et al. Complete closure versus simple closure for perforations during colorectal endoscopic submucosal dissection. Endosc Int Open 2020;8(1):E76-E80.

14. Nomura S, Shimura T, Katano T, et al. A multicenter, single-blind randomized controlled trial of endoscopic clipping closure for preventing coagulation syndrome after colorectal endoscopic submucosal dissection. Gastrointest Endosc 2020;91(4):859-867.

15. Liu M, Zhang Y, Wang Y, et al. Effect of prophylactic closure on adverse events after colorectal endoscopic submucosal dissection: A meta-analysis. J Gastroenterol Hepatol 2020;35(11):18691877.

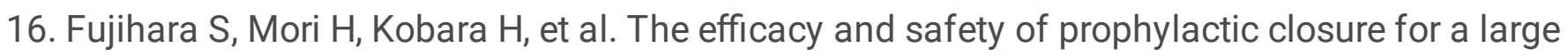
mucosal defect after colorectal endoscopic submucosal dissection. Oncol Rep 2013;30(1):85-90.

17. Nishizawa T, Ochiai Y, Uraoka T, et al. Endoscopic slip-knot clip suturing method: prospective pilot study (with video). Gastrointest Endosc 2017;85(2):433-437.

18. Nishizawa T, Uraoka T, Sagara S,et al. Endoscopic slipknot clip suturing method: an ex vivo feasibility study (with video). Gastrointest Endosc 2016;83(2):447-450.

19. Nishizawa T, Uraoka T, Suzuki $H$, et al. New endoscopic suturing method: slip knot clip suturing. Gastrointest Endosc 2015;82(3):570-571. 
20. Kinoshita S, Nishizawa T, Fujimoto A, et al. Efficacy of mucosa-submucosa clip closure method after gastric endoscopic submucosal dissection. World J Gastrointest Endosc 2020;12(1):17-22.

21. Nishizawa T, Banno S, Kinoshita S, et al. Feasibility of endoscopic mucosa-submucosa clip closure method (with video). Endosc Int Open 2018;6(8):E1070-E1074.

22. Akimoto T, Goto O, Sasaki M, et al. "Hold-and-drag" closure technique using repositionable clips for large mucosal defects after colonic endoscopic submucosal dissection. Endosopy Int Open 2016;04:E1068-E1072.

23. Tanaka S, Kashida H, Saito Y, et al. JGES guidelines for colorectal endoscopic submucosal dissection/endoscopic mucosal resection. Dig Endosc 2015;27(4):417-434.

24. Fujimoto K, Fujishiro M, Kato M, et al. Guidelines for gastroenterological endoscopy in patients undergoing antithrombotic treatment. Dig Endosc. 2014Jan;26(1):1-14.

25. Kato M, Uedo N, Hokimoto S, et al. Guidelines for Gastroenterological Endoscopy in Patients Undergoing Antithrombotic Treatment: 2017 Appendix on Anticoagulants Including Direct Oral Anticoagulants. Dig Endosc. 2018 Jul;30(4):433-440.

26. Kantsevoy SV. The development of the overstitch system and its potentials. Gastrointest Endosc Clin N Am 2020;30(1):107-114.

27. Abe S, Saito Y, Tanaka Y, et al. A novel endoscopic hand-suturing technique for defect closure after colorectal endoscopic submucosal dissection: a pilot study. Endoscopy 2020;52(9):780-785.

28. Goto O, Oyama T, Ono H, et al. Endoscopic hand-suturing is feasible, safe, and may reduce bleeding risk after gastric endoscopic submucosal dissection: a multicenter pilot study (with video). Gastrointest Endosc 2020;91(5):1195-1202.

\section{Tables}

Table 1. Characteristics of patients/lesions before propensity-score matching 
Closure group

(97 lesions in 97 patients)
Non-closure group

(122 lesions in 122 patients)
$P$

value

Patients

\begin{tabular}{|c|c|c|c|}
\hline Age, mean $\pm S D$ (range), years & $69.8 \pm 10.7(42-89)$ & $69.7 \pm 11.3(39-88)$ & 0.962 \\
\hline Sex, Male/Female & $64 / 33$ & $74 / 48$ & 0.418 \\
\hline Antithrombotic agents, $\mathrm{n}(\%)$ & $25 \rrbracket 26 \% \rrbracket$ & $18(15 \%)$ & 0.041 \\
\hline \multicolumn{4}{|l|}{ Lesions } \\
\hline Location (colon/rectum) & $85 / 12$ & $84 / 38$ & 0.001 \\
\hline Morphology (0-I/0-Ila) & $21 / 76$ & $14 / 108$ & 0.041 \\
\hline $\begin{array}{l}\text { Histology (adenoma/M/SM1/SM2 or } \\
\text { more/other) }\end{array}$ & $32 / 48 / 8 / 8 / 1$ & $28 / 67 / 10 / 9 / 8$ & 0.388 \\
\hline Specimen size, mean \pm SD (range), $\mathrm{mm}$ & $40.1 \pm 12.1(18-92)$ & $47.7 \pm 16.1(25-101)$ & $<0.001$ \\
\hline Tumor size, mean \pm SD (range),mm & $26.8 \pm 11.3(10-87)$ & $34.8 \pm 16.6(10-92)$ & $<0.001$ \\
\hline $\begin{array}{l}\text { Simultaneous removal of other } \\
\text { polyps*, } n(\%)\end{array}$ & $3(3 \%)$ & $5(4 \%)$ & 1.000 \\
\hline \multicolumn{4}{|l|}{ ESD outcomes } \\
\hline $\begin{array}{l}\text { Procedure time of ESD, mean } \pm \text { SD } \\
\text { (range), min }\end{array}$ & $\begin{array}{l}61.0 \pm 29.0(12- \\
171)\end{array}$ & $85.3 \pm 48.7(11-274)$ & $<0.001$ \\
\hline En bloc resection rate, $\mathrm{n}(\%)$ & 100 & 98 & 1.000 \\
\hline Perforation during ESD, n (\%) & $3(3 \%)$ & $1(1 \%)$ & 0.324 \\
\hline \multicolumn{4}{|l|}{ Outcomes of prophylactic clip closure } \\
\hline Procedure time, mean \pm SD (range), min & $\begin{array}{l}12.4 \pm 5.2(4.0-- \\
25.0)\end{array}$ & \multirow{2}{*}{$\begin{array}{l}- \\
-\end{array}$} & \\
\hline 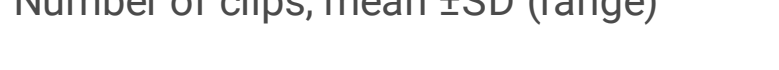 & $9.8 \pm 3.2(3-21)$ & & \\
\hline
\end{tabular}

SD:standard deviation

ESD: endoscopic submucosal dissection

* Endoscopic mucosal resection or polypectomy performed for concomitant lesions

Table 2. Comparison of outcomes before propensity-score matching 


\begin{tabular}{llll} 
& Closure group & Non-closure group & \\
& $(\mathrm{N}=97)$ & $(\mathrm{N}=122)$ & $\begin{array}{l}\mathrm{P} \\
\text { value }\end{array}$ \\
\hline Postoperative adverse events, $\mathrm{n}(\%)$ & $6(6 \%)$ & $35(28 \%)$ & $<0.001$ \\
\hline Delayed bleeding, $\mathrm{n}(\%)$ & $6(6 \%)$ & $33(27 \%)$ & $<0.001$ \\
\hline Minorbleeding, $\mathrm{n}(\%)$ & $5(5 \%)$ & $25(20 \%)$ & 0.001 \\
\hline Major bleeding, $\mathrm{n}(\%)$ & $1(1 \%)$ & $8(7 \%)$ & 0.041 \\
\hline \multicolumn{1}{c}{ Delayed perforation, n (\%) } & 0 & $2(2 \%)$ & 0.504 \\
\hline Abdominal pain (POD 1), n (\%) & $11(11 \%)$ & $13(11 \%)$ & 0.872 \\
\hline Fever (POD 1), n (\%) & $2(2 \%)$ & $12(10 \%)$ & 0.019 \\
\hline Appetite loss (POD 2), n (\%) & $1(1 \%)$ & $6(5 \%)$ & 0.136 \\
\hline $\begin{array}{l}\text { C-reactive protein (POD1), mean } \pm \text { SD } \\
\text { (range) }\end{array}$ & $0.93 \pm 1.7(0.03-$ & $0.74 \pm 1.1(0.03-5.9)$ & 0.316 \\
\hline $\begin{array}{l}\text { White blood cell counts (POD1), mean } \pm \\
\text { SD (range) }\end{array}$ & $7746 \pm 2182(2200-$ & $7716 \pm 2975(2100-$ & 0.931 \\
\hline
\end{tabular}

POD: postoperative day

Table 3. Characteristics of patients/lesions after propensity-score matching 
Patients

\begin{tabular}{llll}
\hline Age, mean \pm SD (range), years & $68.8 \pm 11.0(42-86)$ & $68.5 \pm 11.9(41-84)$ & 0.890 \\
\hline Sex, Male/Female & $38 / 23$ & $38 / 23$ & 1.000 \\
\hline Antithrombotic agents, $\mathrm{n}(\%)$ & $14(23 \%)$ & $13(21 \%)$ & 0.827 \\
\hline Lesions & & & \\
\hline Location (colon/rectum) & $53 / 8$ & $53 / 8$ & 1.000 \\
\hline Morphology (0-I/0-Ila) & $11 / 50$ & $9 / 52$ & 0.625 \\
\hline $\begin{array}{c}\text { Histology (Adenoma/M/SM1/SM2 or } \\
\text { more/other) }\end{array}$ & $20 / 32 / 4 / 4 / 1$ & $19 / 33 / 4 / 4 / 1$ & 0.843 \\
\hline $\begin{array}{c}\text { Specimen size, mean } \pm \text { SD (range), mm } \\
\text { Tumor size, mean } \pm \text { SD (range),mm }\end{array}$ & $41.5 \pm 11.9(23-92)$ & $42.9 \pm 10.7(27-80)$ & 0.503 \\
\hline $\begin{array}{c}\text { Simultaneous removal of other polyps*, } \\
\mathrm{n}(\%)\end{array}$ & $29.1 \pm 11.6(13-87)$ & $29.2 \pm 12.1(14-68)$ & 0.954 \\
\hline
\end{tabular}

ESD outcomes

Procedure time of ESD, mean \pm SD (range), min

$66.5 \pm 28.1(19-157) \quad 68.3 \pm 30.6(11-197) \quad 0.731$

\begin{tabular}{cllr} 
En bloc resection rate (\%) & 100 & 100 & 1.000 \\
\hline Perforation during ESD, $\mathrm{n}(\%)$ & $3(5 \%)$ & 0 & 0.244
\end{tabular}

SD: standard deviation

ESD: endoscopic submucosal dissection

* Endoscopic mucosal resection or polypectomy performed for concomitant lesions

Table 4. Comparison of outcomes after propensity-score matching 


\begin{tabular}{|c|c|c|c|}
\hline & Closure group & losure group & \multirow{2}{*}{$\begin{array}{l}P \\
\text { value }\end{array}$} \\
\hline & $\bigotimes \mathrm{N}=61)$ & $(\mathrm{N}=61)$ & \\
\hline Postoperative adverse events, n (\%) & $5(8 \%)$ & $17(28 \%)$ & 0.008 \\
\hline Delayed bleeding, n (\%) & $5(8 \%)$ & $15(25 \%)$ & 0.025 \\
\hline Minor bleeding, $\mathrm{n}(\%)$ & $4(7 \%)$ & $12(20 \%)$ & 0.032 \\
\hline Major bleeding, n(\%) & $1(2 \%)$ & $3(5 \%)$ & 1.000 \\
\hline Delayed perforation, $\mathrm{n}(\%)$ & 0 & 2 & 0.496 \\
\hline Abdominal pain (POD1) , n (\%) & $7(12 \%)$ & $6(10 \%)$ & 0.769 \\
\hline Fever (POD 1), n (\%) & $2(3 \%)$ & $7(11 \%)$ & 0.163 \\
\hline Appetite loss (POD2), n (\%) & $1(2 \%)$ & $3(5 \%)$ & 0.619 \\
\hline $\begin{array}{l}\text { C-reactive protein (POD1), mean } \pm \text { SD } \\
\text { (range) }\end{array}$ & $0.75 \pm 1.17(0.03-7.6)$ & $0.67 \pm 1.13(0.03-5.9)$ & 0.724 \\
\hline $\begin{array}{l}\text { White blood cell count (POD1), mean } \pm \\
\text { SD (range) }\end{array}$ & $\begin{array}{l}7598 \pm 1955(2200- \\
12500)\end{array}$ & $\begin{array}{l}7849 \pm 3564(2100- \\
29100)\end{array}$ & 0.631 \\
\hline
\end{tabular}

POD: postoperative day

\section{Figures}




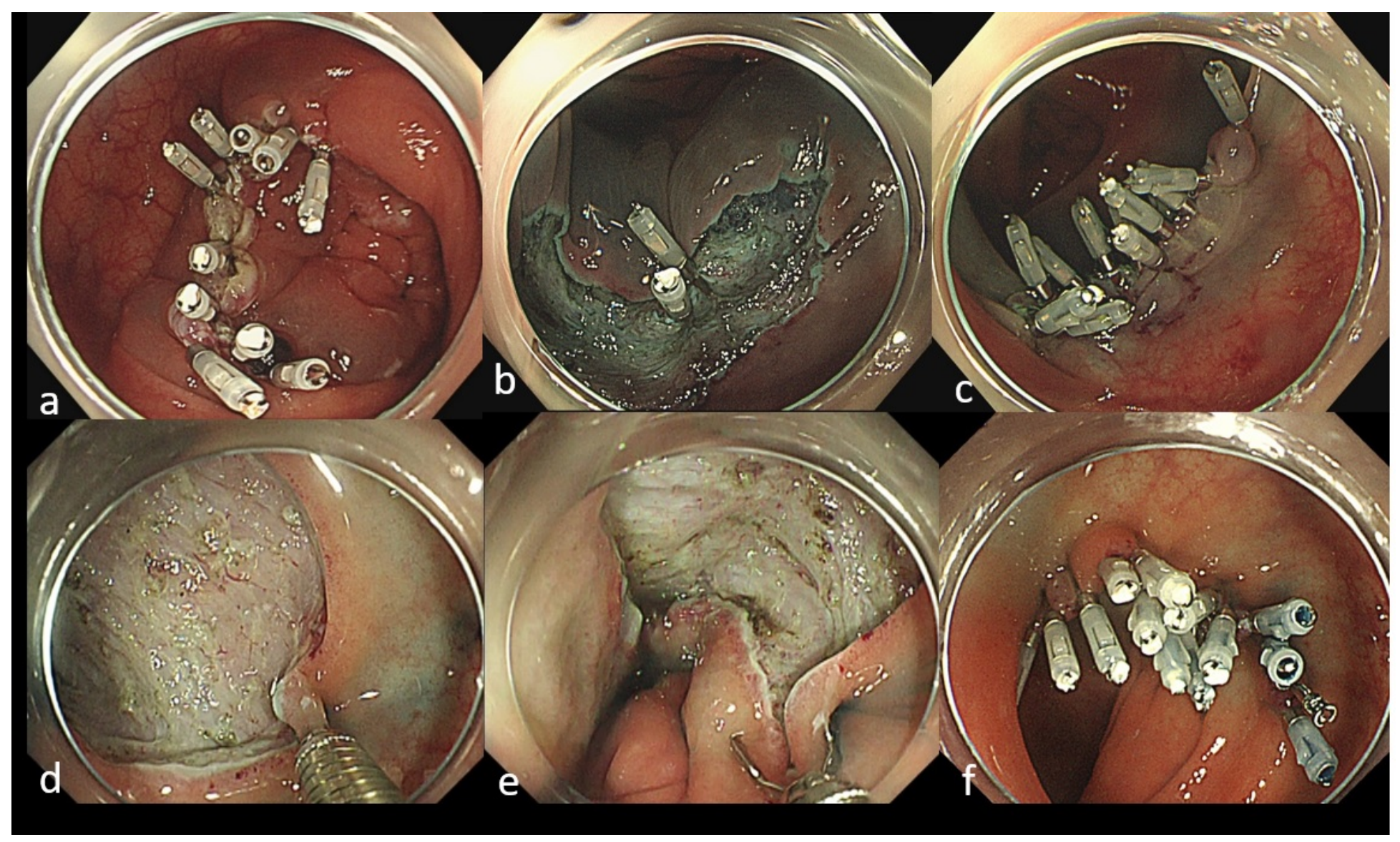

Figure 1

\section{Endoscopic clip closure techniquesused in the present study.}

(a) Conventional method.Complete closure is achieved with conventional clips by directly bridging the two mucosal rims. (b, c) Mucosa-submucosa clip closure method. The first clip is placed at the edge of the mucosal defect (b). Additional clips are placed to achieve complete closure (c). (d, e, f). Hold-and-drag closure technique.The anal side of the mucosal defect is held with the repositionable clip (d).After gently reopening the clip, both edgesare grasped (e). The closure is completed using one repositionable clip and several standard clips (f). 


\section{Enrollment}

Colorectal lesions treated by ESD from January 2018 to August 2020

(259 lesions in 242 patients)

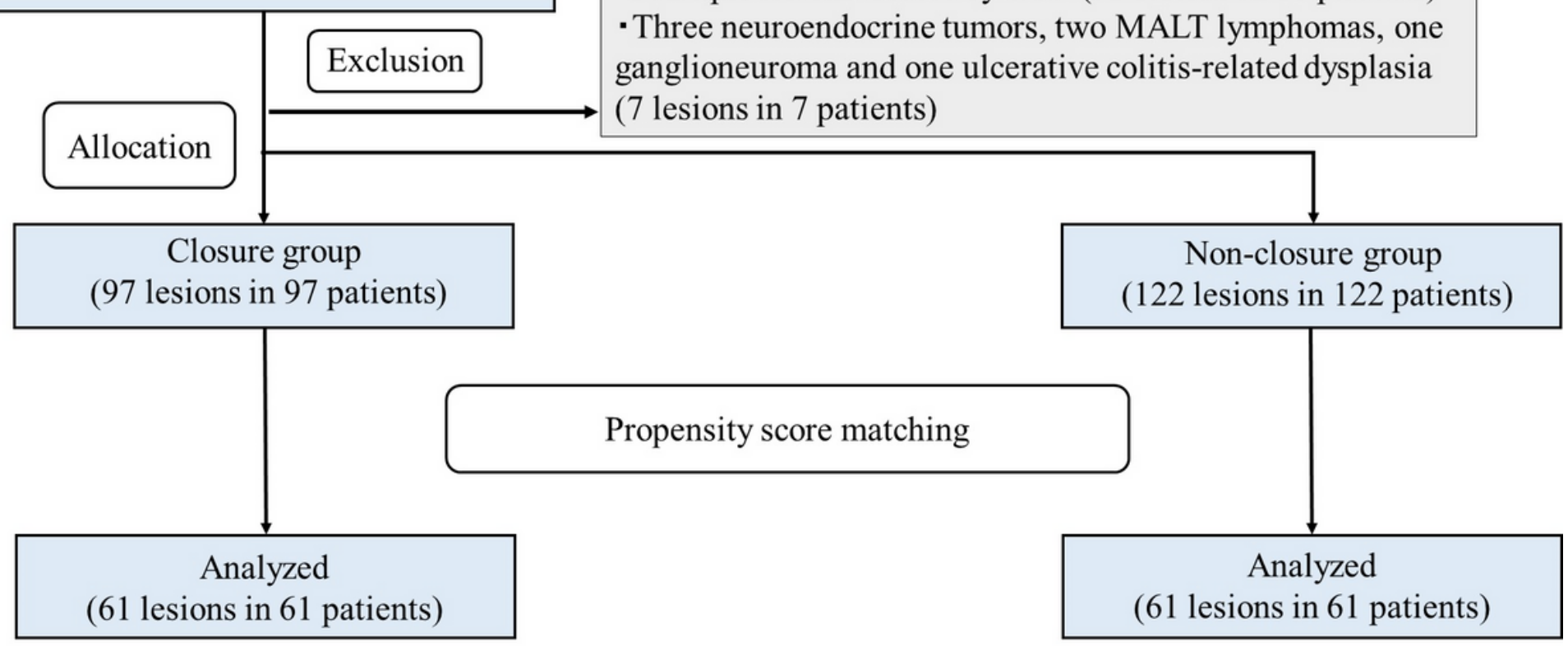

Figure 2

Flow diagram showing patient selection for the study.

The patients were allocated into the closure and non-closure groups, which were compared after propensity-score matching.

ESD, endoscopic submucosal dissection 